\title{
Promoting Transport Kinetics in Li-Ion Battery with Aligned Porous Electrode Architectures
}

Xiao Zhang, ${ }^{1}$ Zhengyu Ju, ${ }^{1}$ Lisa M. Housel, ${ }^{2}$ Lei Wang, ${ }^{3}$ Yue Zhu, ${ }^{1}$ Gurpreet Singh, ${ }^{2}$

Nahian Sadique, ${ }^{2}$ Kenneth J. Takeuchi, ${ }^{2,4}$ Esther S. Takeuchi, ${ }^{2,3,4}$ Amy C. Marschilok, ${ }^{2,3,4}$ Guihua $Y u^{1}$

1. Materials Science and Engineering Program and Department of Mechanical Engineering, The University of Texas at Austin, Austin, TX 78712, United States

2. Department of Chemistry, Stony Brook University, Stony Brook, NY 11794, United States

3. Energy Sciences Directorate, Brookhaven National Laboratory, Upton NY 11973, United States

4. Department of Materials Science and Chemical Engineering, Stony Brook University, Stony Brook, NY 11794, United States

*E-mail: ghyu@austin.utexas.edu 


\section{Experimental section}

Materials synthesis $\mathrm{GO} / \mathrm{Fe}_{3} \mathrm{O}_{4}$ was synthesized through a modified co-precipitation method. $0.5 \mathrm{mmol} \mathrm{FeCl} \cdot 4 \mathrm{H}_{2} \mathrm{O}$ and $1.0 \mathrm{mmol} \mathrm{FeCl}_{3} \cdot 6 \mathrm{H}_{2} \mathrm{O}$ were dissolved and then slowly added to aqueous GO solution containing $8 \mathrm{mg} \mathrm{GO}$. The resulting mixture was then slowly added to $10 \mathrm{~mL} 1 \mathrm{M}$ TEA solution under vigorous stirring. The resulting precipitates was collected and washed after 30 min of stirring.

Electrode fabrication $\mathrm{GO} / \mathrm{Fe}_{3} \mathrm{O}_{4}$, super $\mathrm{P}$ and Nafion aqueous solution were prepared into slurry with mass ratio of 18:1:1. For AGF electrodes, the slurry was dropped onto $\mathrm{Cu}$ foil and subjected to a cold finger, where the bottom of the cold finger was immersed into liquid nitrogen, followed by a freeze-dry process. For GF electrodes, the slurry was directly casted onto $\mathrm{Cu}$ foil and dried. For $\mathrm{F}$ electrodes, $\mathrm{Fe}_{3} \mathrm{O}_{4}$ nanoparticles, super $\mathrm{P}$ and Nafion aqueous solution were mixed at ratio of 14:3:3. The resulting slurry was casted onto $\mathrm{Cu}$ foil and dried in oven. Unless specified, all electrochemical characterization is based on electrodes with $5 \mathrm{mg} \cdot \mathrm{cm}^{-2}$ mass loading.

Cell assembly. All electrochemical measurements were performed in a half-cell configuration. CR2032 coin cell assembly was carried out in an argon-filled glovebox with lithium metal as anode and reference electrode. Celgard 2320 was used as separator between cathode and anode. The electrolyte was $1.0 \mathrm{M} \mathrm{LiPF}_{6}$ dissolved in a mixture of ethylene carbonate and dimethylene carbonate with 1:1 ratio. All electrochemical tests were conducted at room temperature $\left(25^{\circ} \mathrm{C}\right)$ with a voltage range $0.1 \sim 3.1 \mathrm{~V}$. 
Phase identification and morphology characterization. Powder XRD patterns were collected on a Philips Vertical Scanning diffractometer to identify the phase of the assynthesized samples. Scanning electron microscope, STEM (Hitachi S5500) and TEM (JEOL 1400) were used to characterize the morphology of the samples. X-ray fluorescence (XRF) mapping was conducted at the 5-ID beamline of the National Synchrotron Light Source-II (NSLS-II) at Brookhaven National Laboratory. The energy was calibrated using a Fe reference foil at $7112 \mathrm{eV}$. The XRF maps were collected at $7200 \mathrm{eV}$ over a $70 \mu \mathrm{m} \times 70 \mu \mathrm{m}$ area in $2 \mu \mathrm{m}$ increments using an acquisition time of 0.1 s. PyXRF software was used to the Fe contribution of the fluorescence spectra. ${ }^{1}$ XPS was performed using Kratos Axis Ultra DLD X-ray Photoelectron Spectrometer equipped with a monochromatic Al Ka X-ray source $(1,486.7 \mathrm{eV})$ for excitation.

Electrochemical measurements. Rate performance, cycling tests and GITT of asassembled coin cells were tested using a LAND battery test system (CT2001A). GITT was performed under $0.2 \mathrm{~A} / \mathrm{g}$ constant current discharge/charge for $30 \mathrm{~min}$, with rest of 2 h. CV and EIS data were collected using a BioLogic potentiostat (VMP3). For all EIS measurements, the a. c. amplitude was set to $10 \mathrm{mV}$, and frequency range from 1000 $\mathrm{kHz}$ to $10 \mathrm{mHz}$. All electrochemical testing were conducted under room temperature $\left(25^{\circ} \mathrm{C}\right)$.

$\boldsymbol{C} \boldsymbol{V}$ analysis. b-values are calculated through $\mathrm{i}=\mathrm{a} v^{\mathrm{b}}$, where $\mathrm{i}$ is the measured peak current in each CV curve, $v$ is scan rate, and a is adjustable parameters. 


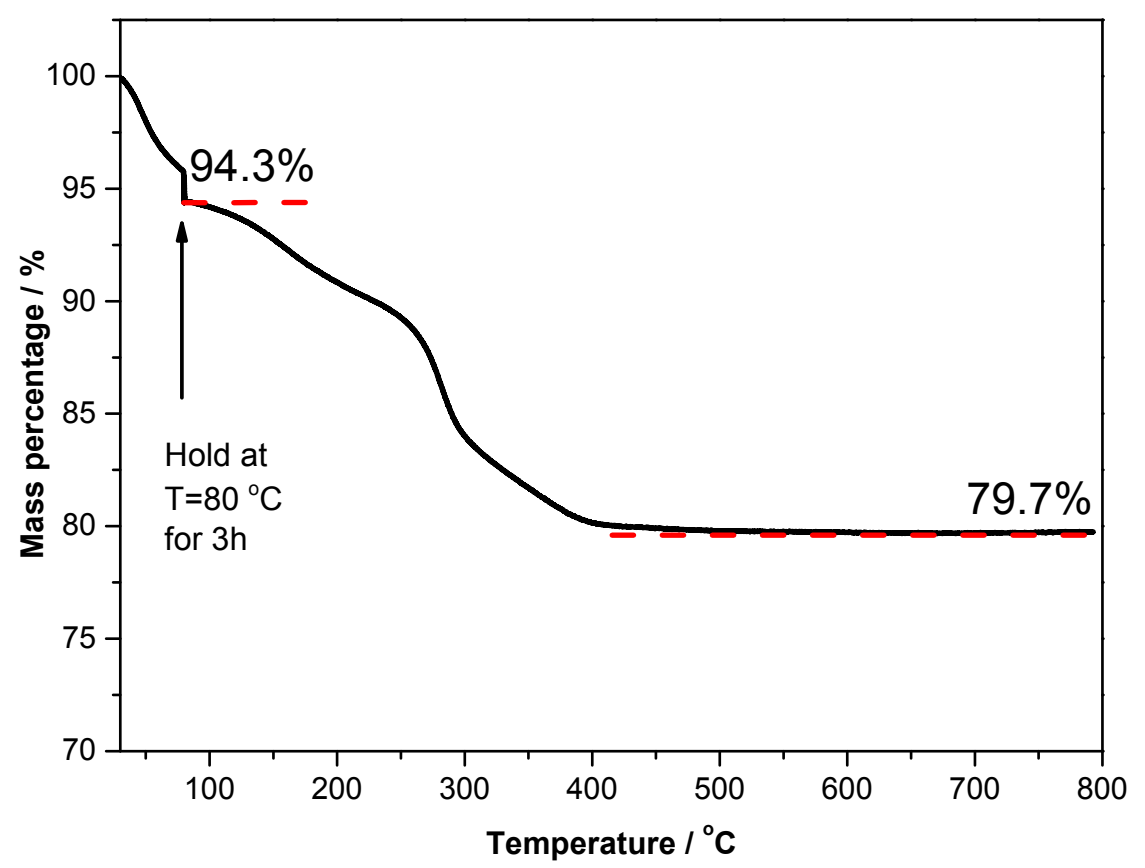

Figure S1. Active material $\left(\mathrm{Fe}_{3} \mathrm{O}_{4}\right)$ is estimated to be $81 \%$ in the as-synthesized nanocomposite through thermogravimetric analysis (TGA). 


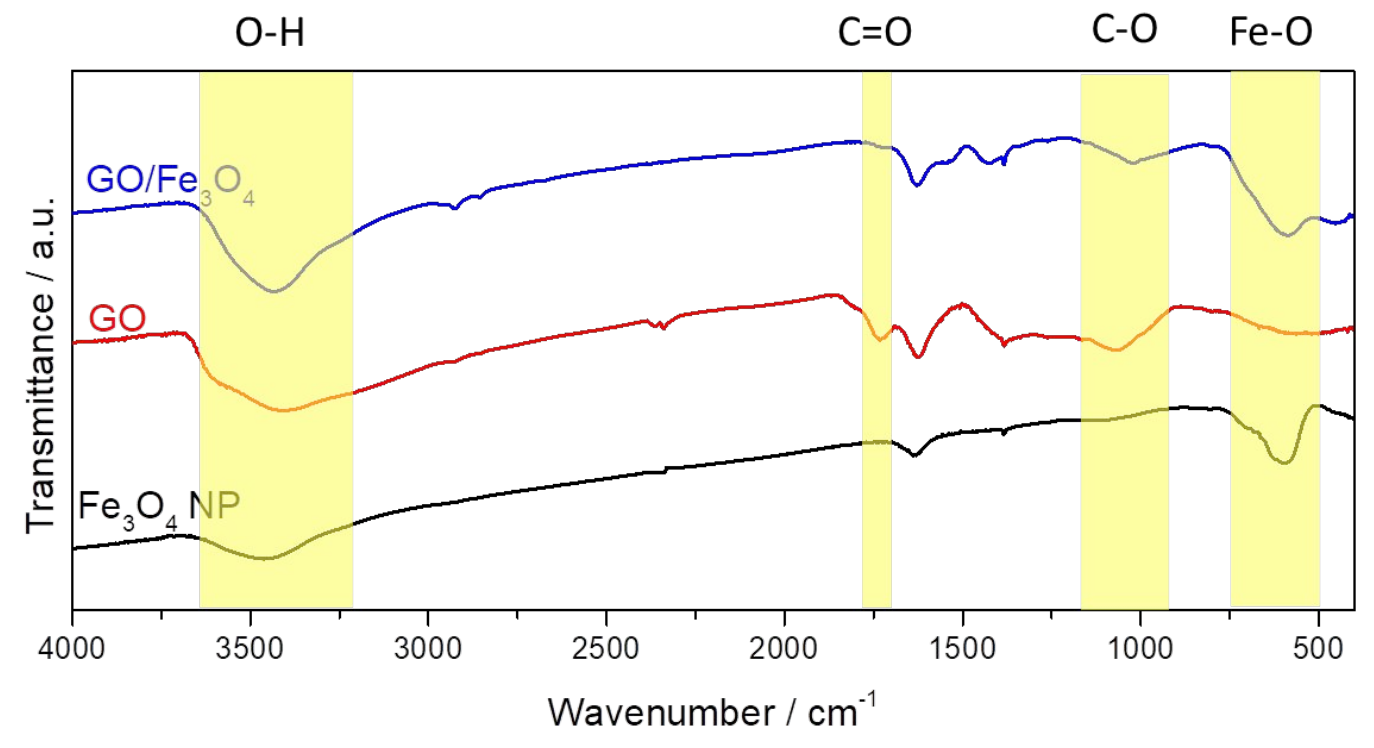

Figure S2. FTIR results reveal strong chemical interaction between $\mathrm{Fe}_{3} \mathrm{O}_{4}$ and GO. 

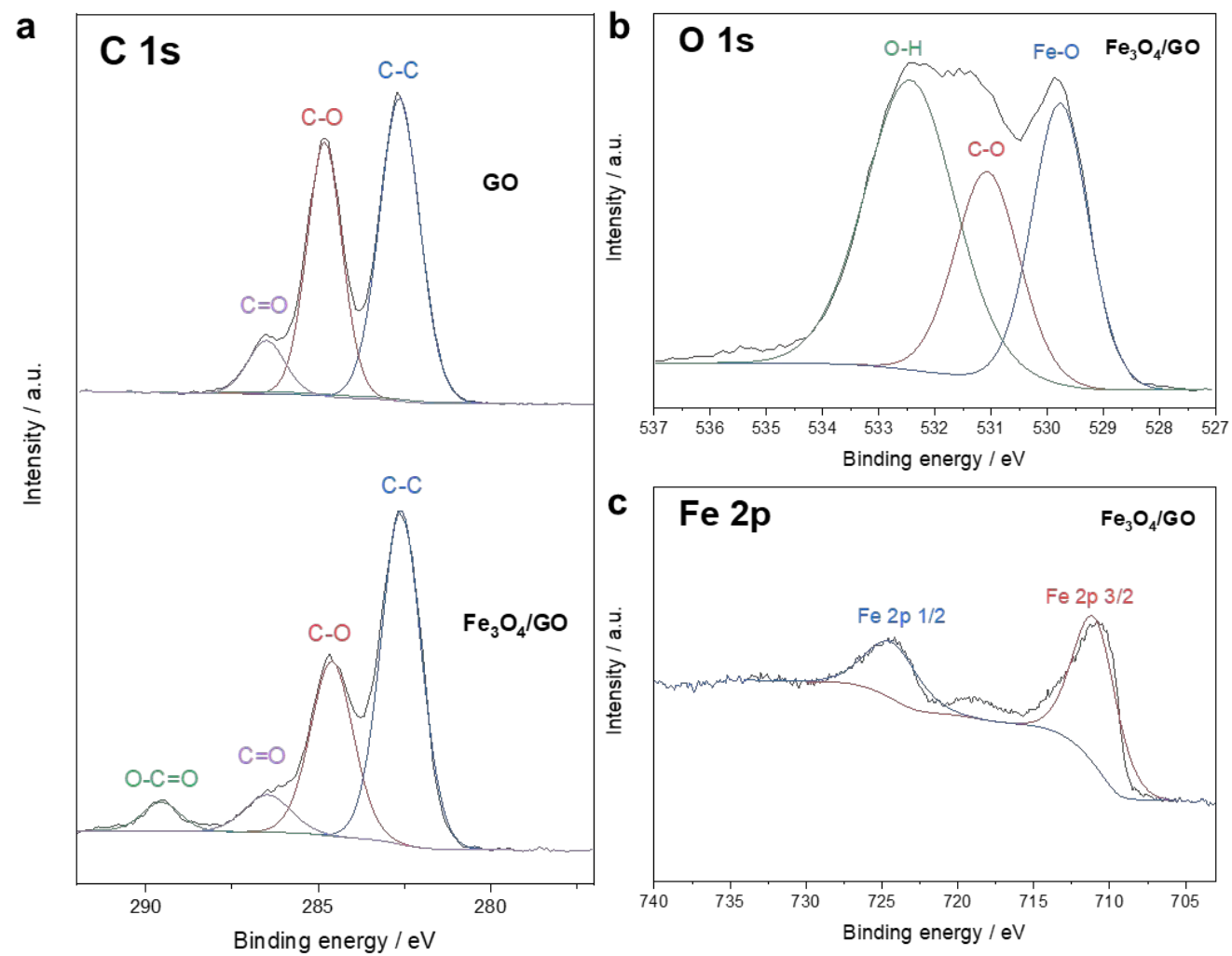

Figure S3. XPS results of (a) $\mathrm{C} 1 \mathrm{~s}$ of $\mathrm{GO}$ and $\mathrm{Fe}_{3} \mathrm{O}_{4} / \mathrm{GO}$, (b) $\mathrm{O} 1 \mathrm{~s}$ and (c) $\mathrm{Fe} 2 \mathrm{p}$ of $\mathrm{Fe}_{3} \mathrm{O}_{4} / \mathrm{GO}$. 

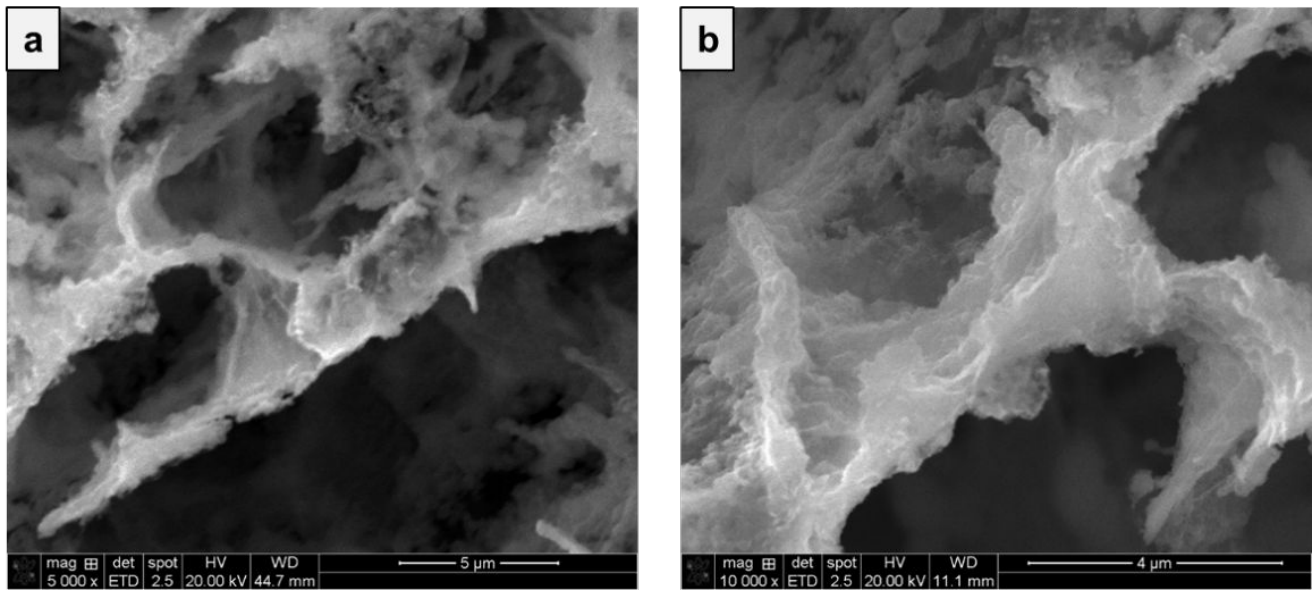

Figure S4. SEM images of aligned channel walls in AGF under different magnifications. 


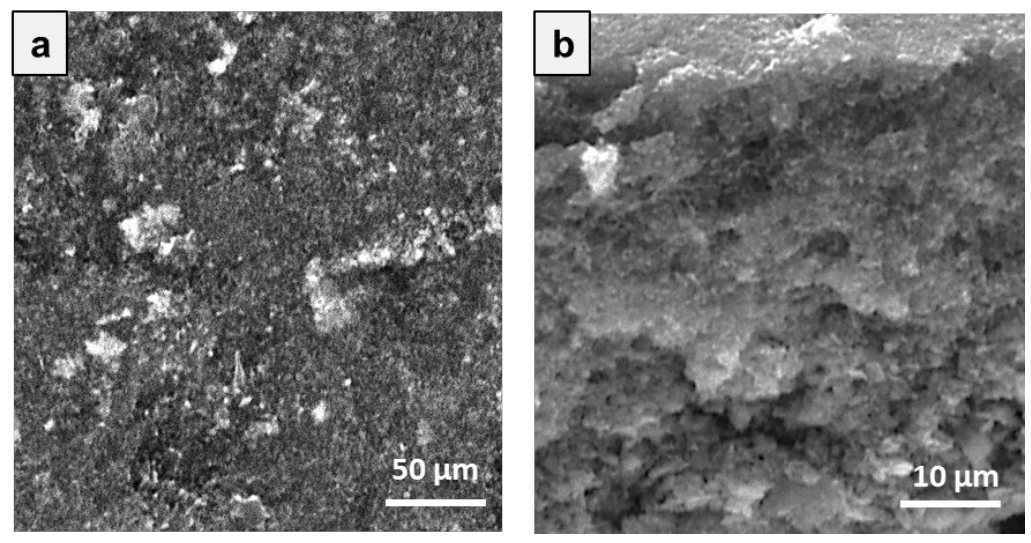

Figure S5. SEM images of GF from (a) top and (b) side views. 

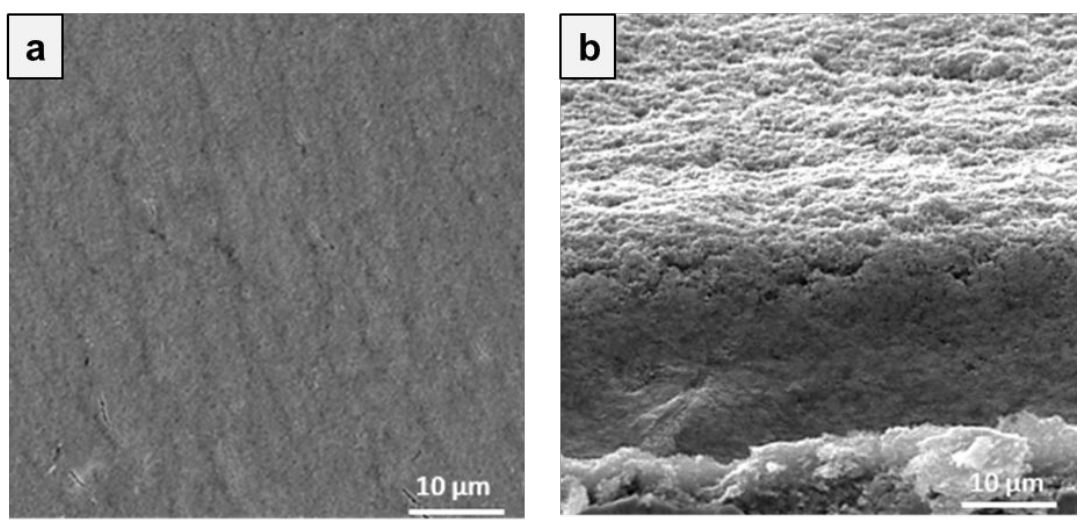

Figure S6. SEM images of F from (a) top and (b) side views. 

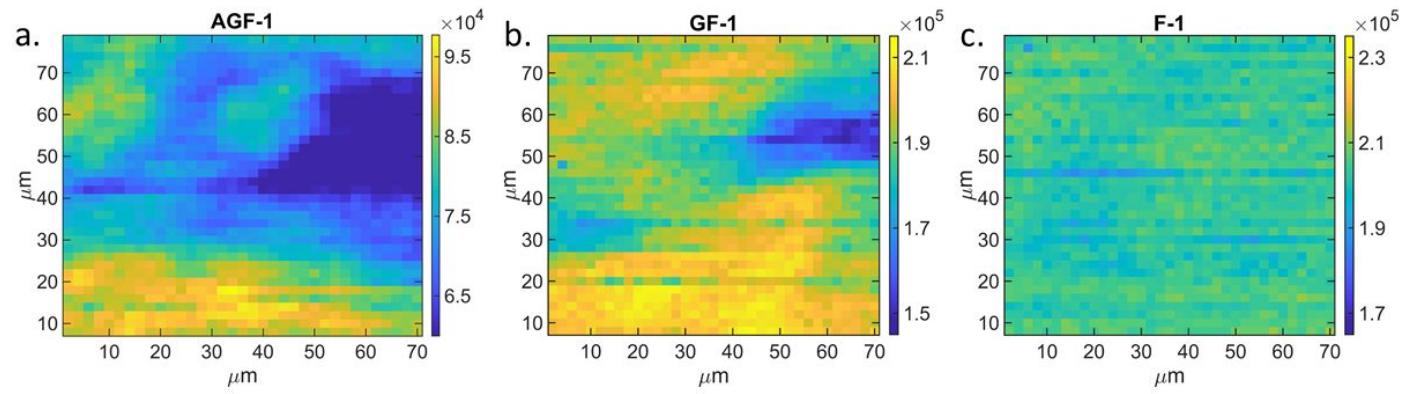

Figure S7. Fe X-ray fluorescence maps of (a) AGF-1, (b) GF-1, and (c) F-1 electrodes. 

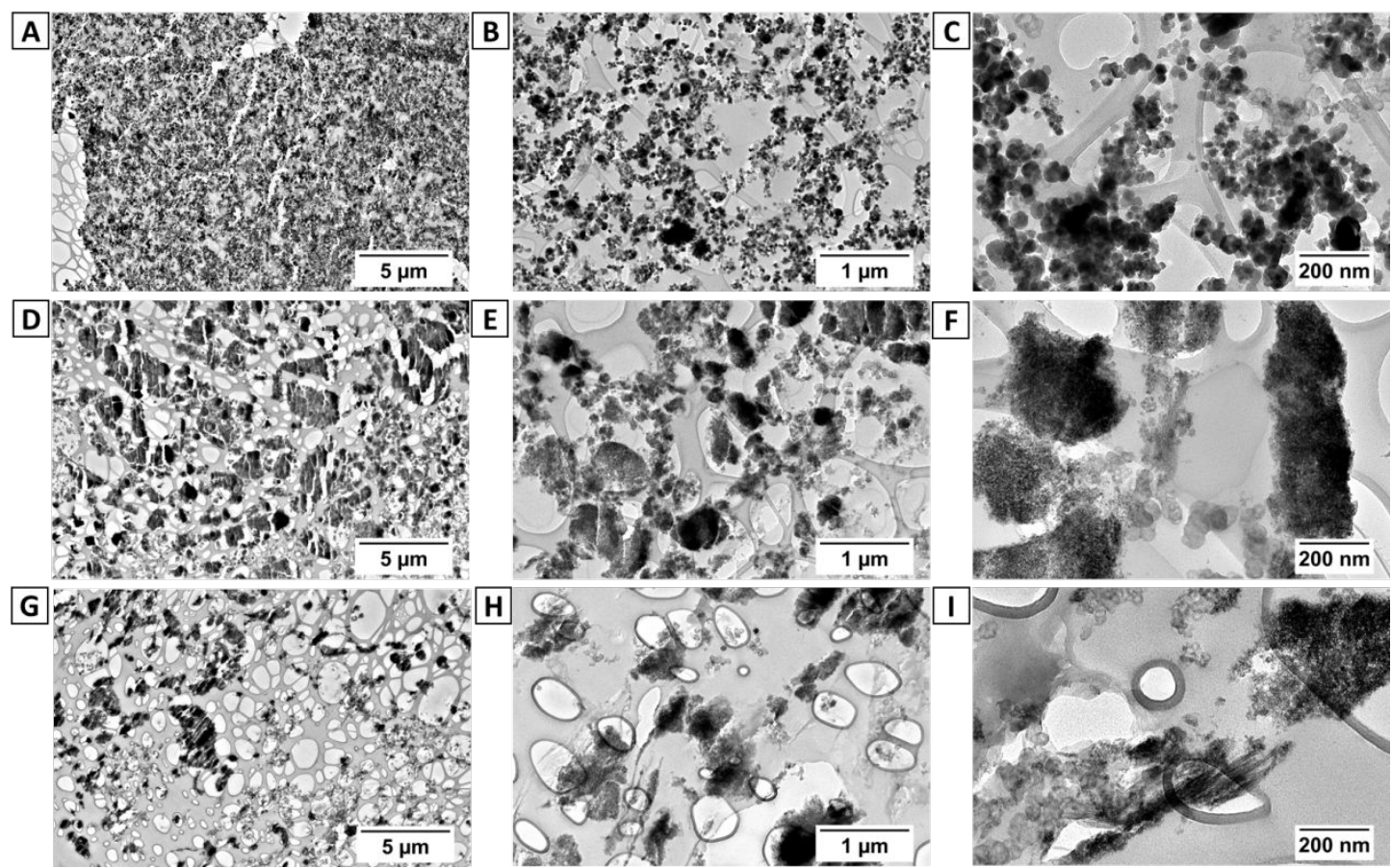

Figure S8. TEM microtome of (a-c) F, (d-f) GF, (g-i) AGF under different magnifications. 
Fe $K \alpha 1$
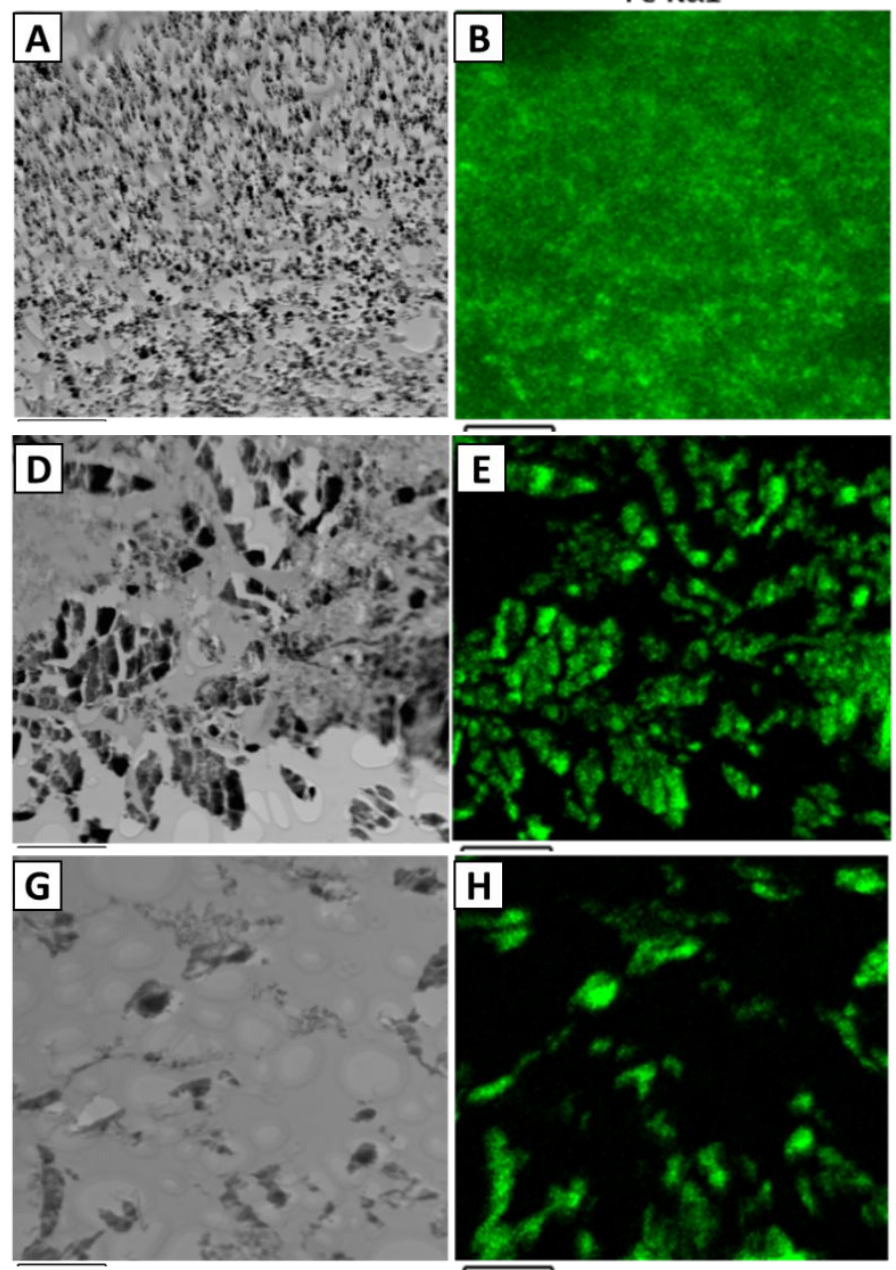

C K $\alpha 12$

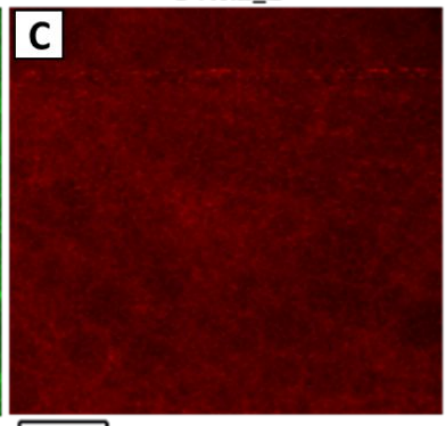

F

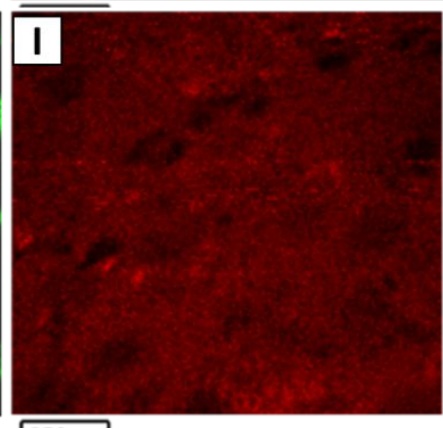

Figure S9. STEM, as well as Fe and C elemental mapping images of (a-c) F, (d-f) GF, and (g-i) AGF electrodes, scale bar $=2 \mu \mathrm{m}$. 

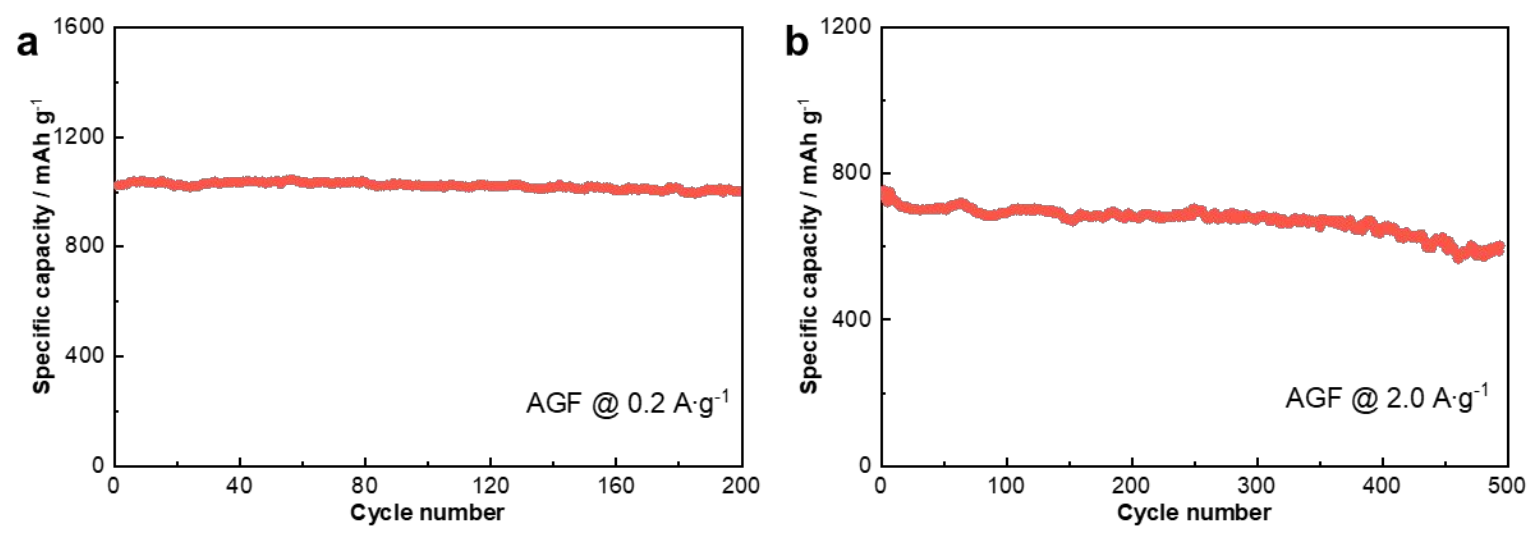

Figure S10. Cycling stability of AGF electrode (a) under $0.2 \mathrm{~A} \cdot \mathrm{g}^{-1}$ for 200 cycles and (b) $2.0 \mathrm{~A} \cdot \mathrm{g}^{-1}$ for 500 cycles. 

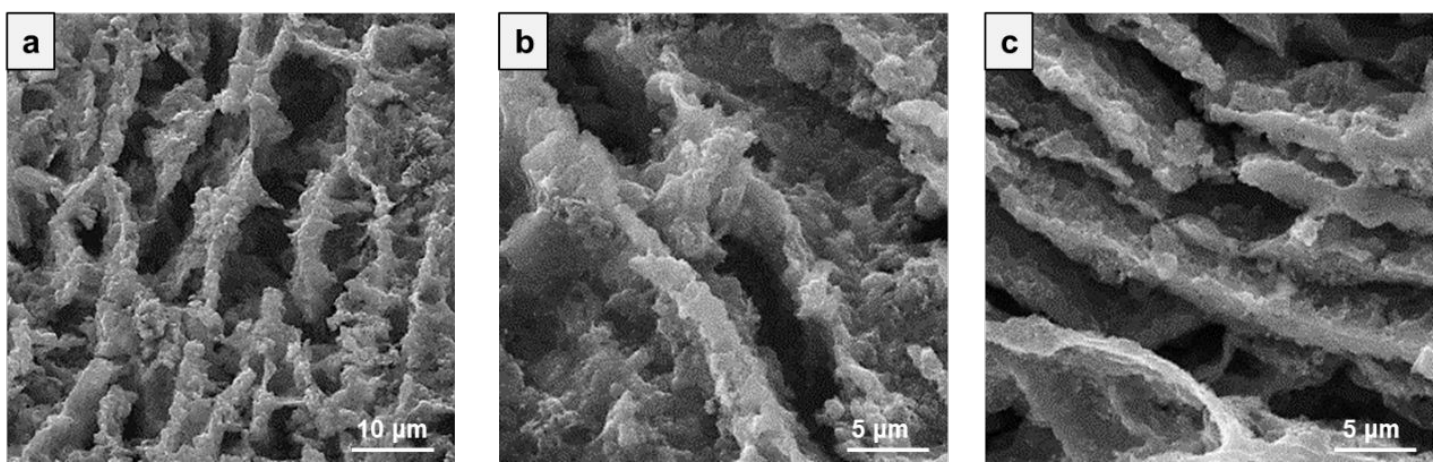

Figure S11. SEM images of AGF after cycling. 

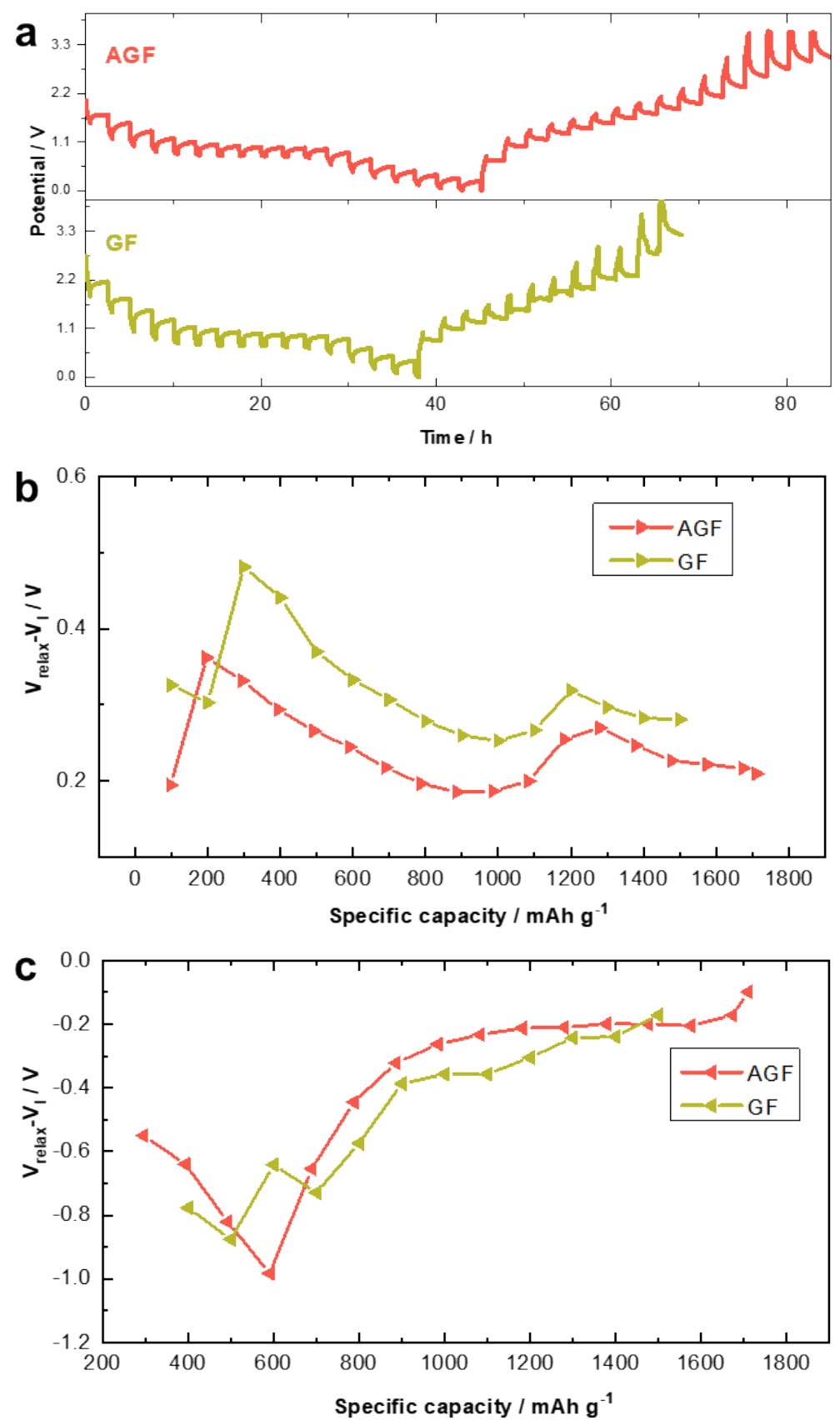

Figure S12. (a) GITT profiles of AGF and GF. $V_{\text {relax }}-V_{I}$ comparison during (b) discharge and (c) charge. 

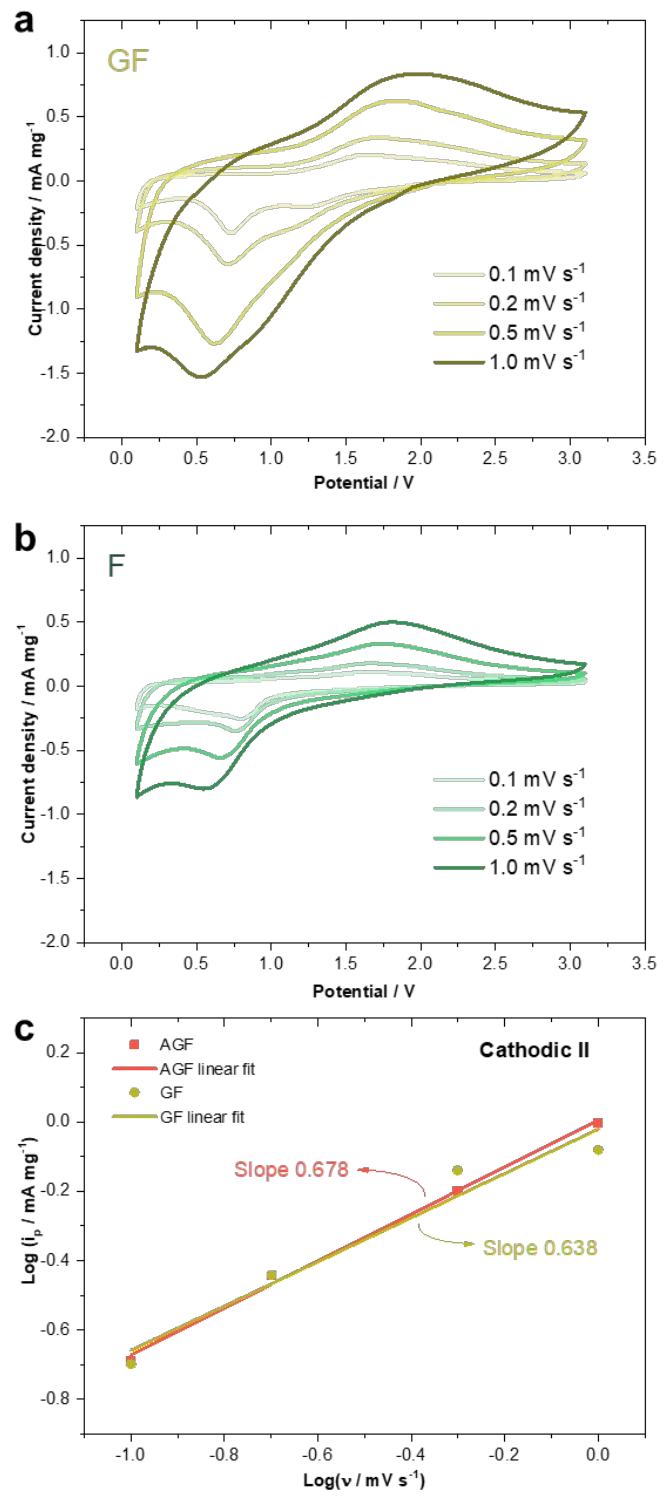

Figure S13. CV profiles of (a) GF and (b) F electrodes under various scan rates. (c) b values of cathodic II peak. 



Figure S14. $\mathrm{N}_{2}$ adsorption-desorption isotherms of the as-prepared (a) AGF and (b) GF electrodes. 

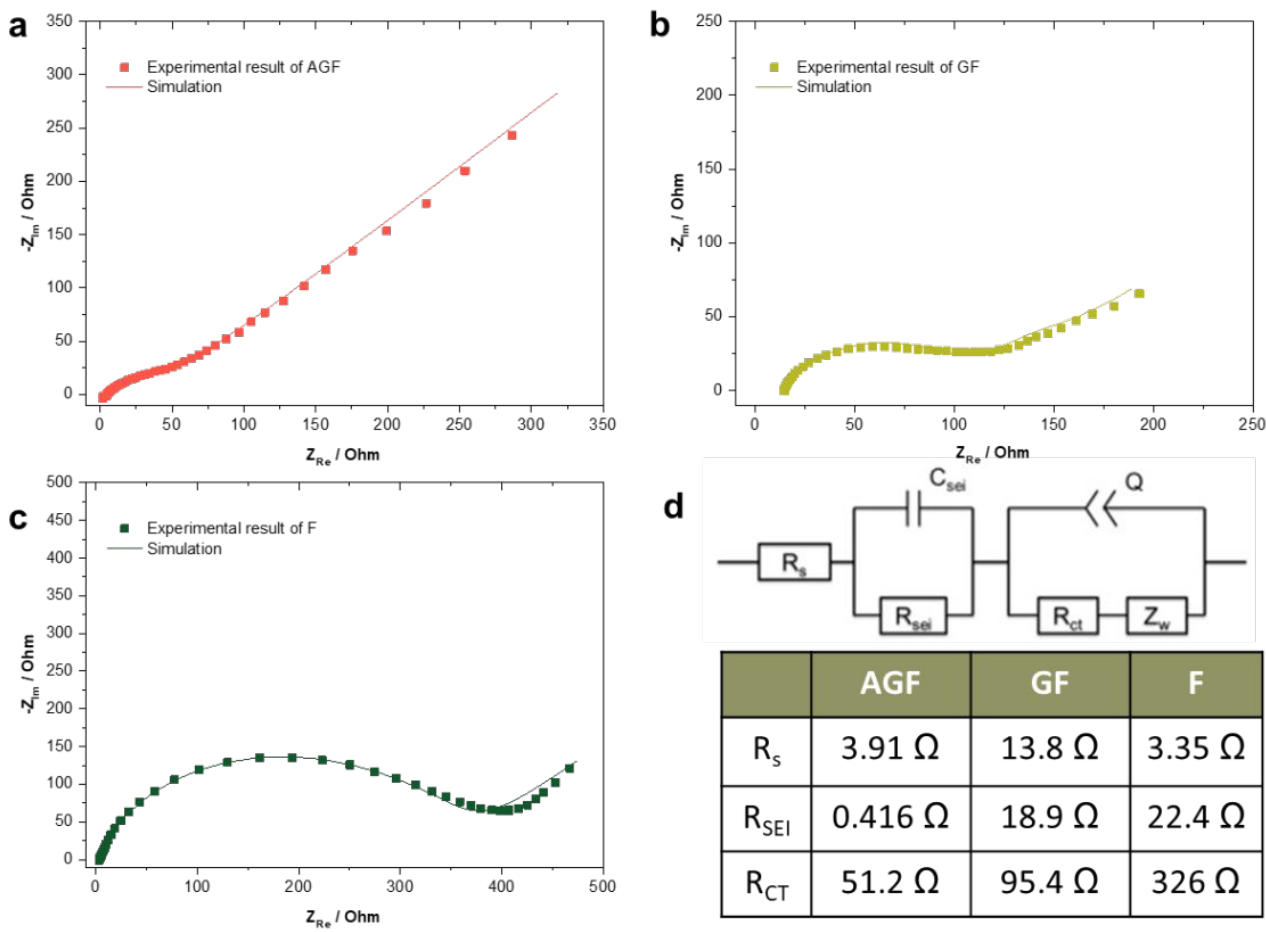

Figure S15. Nyquist plots of (a) AGF, (b) GF and (c) F electrodes. (d) Modified Randle's circuit used for simulation and the estimated impedance values.

\section{Reference:}

1. Li, L., Yan, H., Xu, W., Yu, D., Heroux, A., Lee, W.K., Campbell, S.I. and Chu, Y.S. "PyXRF: Python-based X-ray fluorescence analysis package." X-Ray Nanoimaging: Instruments and Methods III, 2017. 10389, p. 103890U. 